\title{
ESTRESSE NO TRABALHO: ESTUDO COM GESTORES PÚBLICOS DO ESTADO DE MINAS GERAIS
}

\author{
Lyovan Neves Maffia \\ lyovan@yahoo.com.br \\ Universidade Federal de Minas Gerais - Minas Gerais, MG / Brasil \\ Luciano Zille Pereira \\ luciano.zille@unihorizontes.br \\ Faculdade Novos Horizontes - Minas Gerais, MG / Brasil
}

\begin{abstract}
http://dx.doi.org/10.1590/1413-2311.0052014.47163
Recebido em 07/03/2014

Aprovado em 30/09/2014

Disponibilizado em 01/12/2014

Avaliado pelo sistema double blind review

Revista Eletrônica de Administração

Editor: Luís Felipe Nascimento

ISSN 1413-2311 (versão on-line)

Editada pela Escola de Administração da Universidade Federal do Rio Grande do Sul.

Periodicidade: Quadrimestral

Sistema requerido: Adobe Acrobat Reader.
\end{abstract}

\section{RESUMO}

O objetivo deste trabalho consistiu em analisar o estresse no trabalho de gestores públicos que atuam nas secretarias de estado de Minas Gerais. A base teórica relacionada ao estresse ocupacional foi fundamentada em Zille (2005), Chanlat (2005), Cooper et al. (2002, 1988), Couto (1987) e Selye (1959). Em relação à gestão, baseou-se em OCDE (2010), BresserPereira (2009), Madureira e Rodrigues (2006) e Davel e Melo (2005); Rezende (2002) e Marini (2002). Este trabalho pode ser classificado como um estudo descritivo, com abordagem quantitativa. Foram analisados 181 gestores das secretarias de estado de Minas Gerais, sendo que o Modelo Teórico de Explicação do Estresse Ocupacional em Gerentes (MTEG), desenvolvido por Zille (2005), foi a referência principal. Os softwares Excel e SPSS - Statistical Package for the Social Sciences foram utilizados para a análise dos dados. Os resultados evidenciaram que 26,0\% dos gestores pesquisados apresentaram ausência de estresse ocupacional; 26,0\%, nível de estresse leve a moderado; 43,0\%, nível de estresse intenso; e 5,0\% nível de estresse muito intenso. Foram identificadas as principais fontes de tensão excessivas existentes no ambiente de trabalho, os mecanismos de regulação mais utilizados pelos gestores públicos estaduais para enfrentar as situações tensionantes e os indicadores de impacto do estresse na produtividade dos gestores. Este estudo mostrou-se oportuno uma vez que há estudos sobre o estresse ocupacional em gestores da iniciativa privada, mas pouco se sabe sobre o impacto das reformas administrativas do serviço público na saúde laboral dos gestores. Os resultados deste trabalho apresentaram relação direta com outros estudos e espera-se que possa contribuir com o balizamento de projetos institucionais do estado de Minas Gerais para redução ou controle dos níveis de estresse ocupacional dos gestores.

Palavras-chave: Estresse ocupacional; Função gerencial; Estresse em gerentes; Serviço público; Tensão no trabalho. 


\title{
STRESS AT WORK: A STUDY WITH PUBLIC MANAGERS OF STATE OF MINAS GERAIS
}

\begin{abstract}
The objective of this study was to analyze stress during job in public managers who work in secretariats of state of Minas Gerais. The theoretical basis related to occupational stress was based on Zille (2005), Chanlat (2005), Cooper et al. (2002, 1988), Couto (1987) and Selye (1959). Regarding management, drew on OCDE (2010), Bresser-Pereira (2009), Madureira e Rodrigues (2006) e Davel e Melo (2005); Rezende (2002) and Marini (2002). This work can be classified as a descriptive study with a quantitative approach. The Theoretical Model for Explanation of Occupational Stress in Managers (MTEG) developed by Zille (2005), was the main reference. With this approach, 181 managers from secretariats of state of Minas Gerais were analyzed. The softwares Excel and SPSS - Statistical Package for the Social Sciences were used for data analysis. The results evidenced that $26.0 \%$ of the surveyed managers had no occupational stress; $26.0 \%$ had light to moderate stress levels; $43.0 \%$ intense stress; and $5.0 \%$ very intense stress level. The main sources of excessive tension existing in the work environment, the regulatory mechanisms used by most state public managers to face the tensioning situations and indicators of stress impact on the productivity of the managers were identified. This study was proven to be appropriate since there are studies on occupational stress on managers from private enterprise, but little is known about the impact of administrative reforms in the public service on the occupational health of the public managers.
\end{abstract}

Keywords: Occupational stress; Managerial function; Stress in managers; Public service; Tension at work.

\section{ESTRÉS EN EL TRABAJO: ESTUDIO CON GESTORES PÚBLICOS DEL ESTADO DE MINAS GERAIS}

\section{RESUMEN}

El objetivo de este estudio fue analizar el estrés en el trabajo de los gestores públicos que trabajan en Secretarías de Gobierno del Estado de Minas Gerais. La teoría sobre el estrés en el trabajo se basó en Zille (2005), Chanlat (2005), Cooper et al. (2002, 1988), Couto (1987) y Selye (1959). Las informaciones sobre gestión tienen como fuente OCDE (2010), BresserPereira (2009), Madureira y Rodrigues(2006) y Davel y Melo (2005); Rao (2002) y Marini (2002). Este trabajo puede ser clasificado como un estudio descriptivo con abordaje cuantitativo. Se analizó el comportamiento de 181 jefes de departamentos del Gobierno del estado de Minas Gerais y el Modelo Teórico de Explicación de Estrés Ocupacional en Administradores (MTEG) desarrollados por Zille (2005) fue la principal referencia. Las herramientas computacionales Excel y SPSS - Statistical Package for Social Sciences fueron utilizadas para el análisis de datos. Los resultados obtenidos mostraron que el 26,0\% de los directivos encuestados no tenían el estrés en el trabajo; 26,0\%, nivel de estrés leve a moderado; 43,0\%, nivel de estrés intenso; y 5,0\% nivel de estrés muy intenso. Se identificó las principales fuentes de tensión excesiva en el lugar de trabajo, los mecanismos de regulación utilizados por la mayoría de los jefes de órganos estaduales para hacer frente a las situaciones de tensión y los indicadores de impacto del estrés sobre la productividad de eses gestores. Este estudio se demostró oportuno, una vez que hay estudios sobre el estrés laboral REAd | Porto Alegre - Edição 79 - N 3 - setembro/dezembro 2014 - p. 658-680 
Estresse no trabalho: estudo com gestores públicos do estado de Minas Gerais

de los administradores privados, pero poco se sabe sobre el impacto de las reformas administrativas del servicio público en la salud en el trabajo de los administradores públicos. Estos resultados muestran una relación directa con otros estudios y se espera que contribuyan para delinear proyectos institucionales en el estado de Minas Gerais que tengan como objetivo reducir o controlar los niveles de estrés ocupacional de los jefes.

Palabras clave: Estrés ocupacional; Función Gerencial; El estrés en los directivos; Servicio público; El estrés en el trabajo.

\section{INTRODUÇÃO}

O tema central deste estudo é o estresse ocupacional. Nos últimos anos, os estudos sobre o estresse ganharam certa independência em relação às demais áreas do conhecimento, fazendo com que este campo de investigação se tornasse distinto e com características próprias. É importante ressaltar que tal tema está inserido na área da saúde ocupacional e carece de compreensão enquanto um dos aspectos constitutivos dessa área. Também, deve-se partir da premissa de que o estresse ocupacional é situacional, tornando importante situá-lo no atual contexto das organizações, considerando para isso a natureza mutante do trabalho, a busca constante por melhor desempenho e produtividade dos trabalhadores, o novo contrato psicológico a que o trabalhador tem que se submeter e os novos arranjos organizacionais, que visam a maiores e melhores resultados empresariais.

Tal contexto organizacional acaba por submeter os trabalhadores a tensões diárias, as quais apresentam certas idiossincrasias relacionadas à área da atividade e às condições de trabalho. Há que se considerar que diferentes ocupações apresentam diferentes estressores básicos (JOHNSON et al., 2009). De acordo com Lipp (2005, p. 83), “a profissão exercida pela pessoa determina, em grande parte, o nível de stress ao qual ela está sujeita, a sua saúde e o seu bem estar”. No Brasil, estima-se que os gastos com as consequências do estresse cheguem a 3,5\% do PIB nacional/ano (ROSSI, 2009). Estudo realizado pela International Stress Management Association - Brasil, mostrou que 70\% dos brasileiros economicamente ativos sofrem tensão excessiva em seu cotidiano (ISMA, 2010). Isso demonstra que a grande maioria dos trabalhadores brasileiros está em situação favorável ao desenvolvimento de quadros de estresse, ou já possuem quadros instalados.

Entre as ocupações com alta carga de tensão diária estão os gestores, que passam por um mal-estar decorrente de aspectos como a falta de perspectivas de futuro, imprecisão na definição de tarefas e responsabilidades, pouco reconhecimento, clima social deteriorado, insegurança, aumento dos meios de controle e pressão por maior produtividade, aumento da

REAd | Porto Alegre - Edição 79 - N 3 - setembro/dezembro 2014 - p. 658-680 
jornada de trabalho, informatização, integração de funções distintas e eliminação de outras. Além disso, os gestores acabam por atuar num espaço caracterizado, principalmente, pela ambiguidade de demandas e papéis a desempenhar e pela capacidade de mediar contradições (DAVEL e MELO, 2005; CHANLAT, 2005).

A rotina sobrecarregada vivenciada pelos gestores tem resultado em alta incidência de estresse ocupacional nestes trabalhadores (MELO et al., 2011; ZILLE, 2011; ZILLE et al., 2011; ZILLE et al., 2008; ZILE, 2005). Segundo Chanlat (2005), os estudos sobre gestores têm revelado cinco grandes fontes de estresse potencialmente prejudiciais a sua saúde: o próprio trabalho; a tensão entre carreira e vida privada; as relações com os outros; a organização e o contexto social global. Essas cinco fontes de estresse podem ser mediadas pelo próprio indivíduo, pelo apoio social com o qual pode ou não contar e, pela fase do ciclo de vida profissional na qual se encontra.

Há que se considerar que o serviço público brasileiro passa por um momento de profissionalização da função pública, a partir da reforma do aparelho do Estado e das recentes inovações tecnológicas, que imprimiram mudanças no contexto de trabalho. Nos últimos dez anos, o ambiente dessas organizações públicas vem incorporando uma nova dinâmica de trabalho, que pressupõe novas habilidades e competências dos indivíduos (BALASSIANO et al., 2011). Em âmbito mundial, a abordagem gerencial, também conhecida como 'nova administração pública', vem substituindo a perspectiva burocrática anterior, o que também se torna realidade no caso brasileiro (BRESSER-PEREIRA, 2009; ABRUCIO, 2006).

Um exemplo de reforma administrativa é o ‘Choque de Gestão’ e suas derivações que desde 2003 vem sendo implementado no estado de Minas Gerais, mas pouco se sabe sobre o impacto de tais mudanças na saúde dos servidores. Disso, surge uma importante lacuna a ser investigada: Quais são os índices de estresse ocupacional, suas causas, principais sintomas, mecanismos de regulação e indicadores de impactos na produtividade dos trabalhadores que exercem a função de gestor nas secretarias de estado de Minas Gerais?

Portanto, este estudo mostra-se oportuno uma vez que os resultados podem subsidiar a implementação de políticas complementares na área de gestão de pessoas, contribuindo para sedimentar as mudanças já realizadas e para balizar os projetos institucionais visando reduzir ou controlar os níveis de estresse ocupacional dos gestores. 
Estresse no trabalho: estudo com gestores públicos do estado de Minas Gerais

\section{REFERENCIAL TEÓRICO}

Este tópico aborda as duas variáveis que serão analisadas neste estudo: a função gerencial no serviço público e o estresse ocupacional, abordadas separadamente.

\subsection{Função gerencial no serviço público}

As tentativas de reformar o Estado e a administração pública são frequentes na história recente do Estado moderno. Também tem se tornado uma experiência frequente a incapacidade destas políticas de promover ganhos substanciais de performance no setor público (REZENDE, 2002).

Após a Segunda Guerra Mundial, houve grande empenho do Estado, enquanto ator social e organizador da sociedade, para sanar os grandes problemas econômicos nos diversos países. Na busca por estabilidade e crescimento econômico e sob a influência das doutrinas econômicas de Keynes, o Estado interveio fortemente na economia, para garantir a proteção social e gerar o pleno emprego. Este Estado Providência não resolveu o problema da exclusão social e acabou por aumentar a despesa pública (MADUREIRA; RODRIGUES, 2006).

Nos anos de 1970, a grave crise fiscal, a persistência da cultura burocrática em meio a práticas patrimonialistas e o profundo déficit de desempenho, em termos de quantidade e qualidade na prestação de serviços públicos, dentre outros fatores, contribuíram para a crise dessa tipologia de Estado. Visando superar a crise, surgiram iniciativas de reestruturação econômica e a reconfiguração das estratégias empresariais, introduzindo no debate sobre o Estado Contemporâneo, já no início dos anos de 1980, questões relativas às necessidades de incorporação de novos papéis, de abandono de outros e, sobretudo, a exigência de reorganização. Essa crise colocou em questionamento o modo tradicional de organização e gestão governamental, a partir do esgotamento do modelo burocrático de administração pública vigente (MARINI, 2002).

A partir dos anos de 1980, em quase todas as democracias avançadas e em algumas democracias novas, começou a ser implementado um grande conjunto de mudanças na gestão pública. Algumas dessas reformas foram orientadas para o mercado, como a liberalização do comércio e a privatização, e outras se voltaram para a capacitação do Estado, como o ajuste fiscal e as reformas da gestão pública (BRESSER-PEREIRA, 2009).

As demandas por mudanças partiram de dentro e de fora dos Estados-nação. A mudança partiu de dentro à medida que o crescimento econômico e a democracia avançaram,

REAd | Porto Alegre - Edição 79 - N 3 - setembro/dezembro 2014 - p. 658-680 
que os cidadãos, na sociedade civil ou na esfera pública, tornaram-se mais ativos e exigentes e que as crises induziram à transformações e fizeram com que os formuladores de políticas aprendessem com os erros cometidos. Também as mudanças partiram de fora porque as experiências bem-sucedidas em um país puderam ser adaptadas e assimiladas por outros, já que a globalização forçou as empresas comerciais a competirem e exigirem que os governos nacionais dessem suporte a essa competição (BRESSER-PEREIRA, 2009).

Nos anos de 1990, um conjunto expressivo de experiências nacionais de reforma administrativa consolidou uma nova onda de reformas no setor público, centrada nas ideias do New Public Management. As reformas deveriam construir um setor público com maior performance e mais voltado para atender os cidadãos com melhores serviços públicos. Este princípio produziu as reformas gerenciais na Nova Zelândia e na Austrália; o Next Steps, na Inglaterra; o National Performance Review, nos EUA; e a reforma gerencial de 1995, no Brasil (REZENDE, 2002).

Nesta Nova Gestão Pública o Estado teve de utilizar práticas gerenciais modernas, sem perder de vista sua função eminentemente pública. “Gerenciar” adquire um sentido bem diferente de “Controlar”. Não se trata, porém, da simples importação de modelos idealizados do mundo empresarial, mas do reconhecimento de que as novas funções do Estado em um mundo globalizado exigem novas competências gerenciais, novas estratégias administrativas e novas instituições (BRESSER-PEREIRA, 2009).

De acordo com Abrúcio (1997), o desenvolvimento das habilidades gerenciais do administrador público - em particular os de nível médio e os do alto escalão burocrático - é uma tendência do modelo gerencial. Os funcionários precisam ser versáteis e desempenhar as funções de administrador, atuando em conformidade com os regulamentos rotineiros; de produtor, ligada ao aumento da produtividade com qualidade; de inovador, capaz de encontrar novas respostas e modernizar o fluxo de decisões; e de integrador, habilitado a congregar sua equipe a atuar em conjunto na busca de um objetivo comum.

É importante considerar que existem alguns entraves que dificultam o desempenho desse novo papel. No Brasil, é possível identificar alguns fatores próprios à cultura que bloqueiam, de alguma forma, a iniciativa dos gestores, como a cultura autoritária, coronelista e paternalista; a cultura organizacional individualista, personalista, conservadora e centralizadora; a estrutura de poder corporativista; e a visão de curto prazo (ou imediatista) dos resultados. Tais fatores acabam se tornando dificultadores do processo de gestão e geradores de tensão no trabalho (DAVEL; MELO, 2005).

REAd | Porto Alegre - Edição 79 - N 3 - setembro/dezembro 2014 - p. 658-680 
Estresse no trabalho: estudo com gestores públicos do estado de Minas Gerais

Com a Nova Gestão Pública as políticas e os programas buscam atingir seus objetivos por meio de dois mecanismos complementares: promoção de medidas concretas de ajuste fiscal; e realização de uma mudança institucional. O primeiro mecanismo decorre da implementação de iniciativas voltadas para o controle e a redução dos gastos com o aparato burocrático, enquanto o segundo tem o intuito de criar uma estrutura institucional capaz de organizar o funcionamento da administração pública orientada pela performance (REZENDE, 2002).

De acordo com a OCDE (2010), a administração pública brasileira está em uma fase inicial de transição de um sistema baseado em normas regulamentares e procedimentos administrativos para a gestão baseada em resultados. Está sendo utilizado o contrato de gestão como instrumento de controle dos gestores públicos, com um rígido monitoramento sobre o desempenho, havendo mais delegação de autoridade e responsabilidade. Tais mudanças exigem que o administrador público desempenhe um novo papel, mais empreendedor e estratégico.

Em Minas Gerais, o atual modelo de gestão já adota a contratualização de resultados e é um exemplo de transição administrativa. Em 2002, após diagnóstico realizado pelo Banco de Desenvolvimento de Minas Gerais, foi verificada a necessidade de um ‘Choque de Gestão’ para reverter o deficit orçamentário do estado (CAMPOS e GUIMARÃES, 2009). De acordo com Vilhena et al. (2006, p. 21), o Choque de Gestão é “um conjunto integrado de políticas de gestão pública orientado para o desenvolvimento” e começou a ser implementado em 2003. A preocupação central era com o ajuste fiscal, a estabilidade econômica e, também, com o aumento de bem-estar de forma integrada à responsabilidade fiscal e com ganhos de eficiência, baseados em transformações estruturais (VILHENA et al., 2006).

Em 2007, foi implantada a Segunda Geração do Choque de Gestão, denominada de ‘Estado para Resultados’. Na prática, houve alteração na organização das ações da administração pública, sendo que as secretarias e demais órgãos do Estado passaram a formar um sistema coordenado, onde não existem mais processos realizados de forma autônoma, sem conexão com a estratégia geral. O Estado para Resultados tem como pilares a preocupação com a qualidade fiscal e com a gestão eficiente, de tal forma, a maximizar o retorno social para o gasto público (MINAS GERAIS, 2008).

O Estado para Resultado possui um instrumento de contratualização de resultados celebrado entre dirigentes de órgãos e entidades do poder executivo e as autoridades que sobre eles tenham poder hierárquico ou de supervisão, denominado 'Acordo de Resultados'. 
Os acordos têm como objetivo estabelecer metas alinhadas ao planejamento estratégico do Governo e, medir o desempenho de cada órgão e entidade da Administração Pública Estadual (MINAS GERAIS, 2008).

Já em 2011 foi implementada a terceira e atual etapa do Choque de Gestão, denominada ‘Gestão para a Cidadania'. A premissa desta etapa é a 'governança em rede’ que se subdivide em dois eixos de trabalho: a gestão regionalizada e a gestão participativa. Buscase a governança a partir do foco regional com a interlocução e participação ativa dos integrantes governamentais entre si e destes com a sociedade civil organizada (MINAS GERAIS, 2012).

\subsection{Estresse ocupacional}

Selye (1959), um dos precursores no estudo do estresse, foi o primeiro a utilizar o termo reação de estresse ao elaborar sua teoria sobre os processos bioquímicos ocorridos durante os períodos de adaptação do corpo. Selye (1959, p. 64) definiu o estresse como um “estado manifestado por uma síndrome específica, constituído por todas as alterações nãoespecíficas produzidas num sistema biológico”. Esta síndrome é decorrente das exigências feitas ao equilíbrio interno do corpo. Formulou uma teoria ampla baseada na Síndrome de Adaptação Geral (SAG) com três estágios. A Reação de Alarme, que é o estágio inicial de mobilização do corpo para a luta ou a fuga, quando há uma descarga hormonal que predispõe o indivíduo a enfrentar a situação adversa em que se encontra; o Estágio de Resistência, que ocorre quando a situação não é prontamente solucionada e o indivíduo continua predisposto a enfrentá-la; e o Estágio de Exaustão, quando o indivíduo não consegue encerrar essa batalha, o nível de resistência vai aos poucos enfraquecendo, o dispêndio de energia é muito grande e o indivíduo não consegue manter os níveis de prontidão anteriores, chegando-se à exaustão (SELYE, 1959).

Selye (1959) abordou o estresse como uma resposta natural do corpo a estímulos externos ou internos de maior intensidade para o indivíduo. A concepção do ser humano nestes estudos é a de um ser que deve estar em equilíbrio com a natureza. O estresse é entendido como algo natural no processo de adaptação do indivíduo ao ambiente. Mas é importante considerar que outras formas de abordagem do estresse também surgiram, algumas apenas complementam as ideias de Selye outras têm uma visão diferenciada sobre o fenômeno.

REAd | Porto Alegre - Edição 79 - N 3 - setembro/dezembro 2014 - p. 658-680 
Estresse no trabalho: estudo com gestores públicos do estado de Minas Gerais

A abordagem biológica do estresse está embasada nas reações fisiológicas do organismo diante de uma perturbação à homeostase e na tentativa de promover sua restauração. As reações de adaptação orgânica têm por objetivo realizar a manutenção ou a retomada do equilíbrio interno do organismo. Na concepção psicológica do estresse, a ênfase está no processo de avaliação e interpretação dos estímulos pelas funções cognitivas e estrutura psíquica do indivíduo. Nestes casos, o aparecimento do estresse está condicionado às características do estímulo e ao padrão de interpretação da pessoa; ou seja, como ela avalia e percebe subjetivamente o estímulo. Já a concepção social do estresse está relacionada em parte com os estressores sociais, ou seja, reações de estresse ligadas ao aspecto social e por outra parte com a competência social para seu controle. O ambiente social, do qual resultam estressores, reflete as condições culturais e socioeconômicas da vida e do trabalho (SAMULSKI et al., 1996).

Couto (1987, p. 16.) define o estresse como "um estado em que ocorre um desgaste anormal da máquina humana e/ou uma diminuição da capacidade de trabalho, ocasionados basicamente por uma incapacidade prolongada de o indivíduo tolerar, superar ou se adaptar às exigências de natureza psíquica existentes no seu ambiente de vida”. Continuando com o entendimento de Couto (1987, p.95), ele considera que “o estresse tem origem na relação desproporcional entre as exigências psíquicas do ambiente em que a pessoa vive e a estrutura psíquica do indivíduo”. Dois fatores são incorporados nesta definição, o tempo e a intensidade.

Para os propósitos deste estudo, o estresse considerado como aspecto natural do cotidiano dos indivíduos, gerado em situações pontuais e corriqueiras não será de interesse. Como coloca Couto (1987, p. 17), “o stress não é a resposta de adrenalina diante de ameaças; este tipo de reação já foi conceituado como stress, mas é preferível que seja conceituado como reação de alarme”. Tal reação é importante para o processo adaptativo do indivíduo ao ambiente, mas é uma reação fisiológica natural dos seres humanos. O foco deste estudo será o estresse disfuncional, o distresse, assim como definido por Arroba e James (1994) e Couto (1987), gerado pelo trabalho, produzido ao longo do tempo e que traz consequências negativas para a saúde e o bem-estar dos indivíduos. O estresse, aqui entendido enquanto disfuncional é um desgaste do organismo humano provocado por uma tensão crônica, na maioria das vezes, ou uma tensão aguda de grande intensidade.

É importante considerar que situações semelhantes podem desencadear reações diferentes nas pessoas. Os estímulos do meio ambiente não afetam da mesma forma todos os 
indivíduos, pois há diferentes percepções e interpretações das situações vivenciadas. Fatores como hereditariedade, sexo, idade, vigor físico, enfrentamento, lócus de controle e alguns outros influenciam a vulnerabilidade ao estresse. Em relação às experiências subjetivas, o aparelho psíquico de cada indivíduo tem percepções distintas de eventos semelhantes e de um mesmo evento também, vivenciado por outra pessoa. Independente da intensidade dos eventos, eles são percebidos e vivenciados de forma diversa pelos indivíduos. Quanto ao grau de manifestação do estresse, há que se destacar a importância do significado atribuído pelo indivíduo aos eventos de sua vida (RIO, 1995).

Samulski et al. (1996, p. 8) consideram que, analisando a pessoa como um parâmetro, fica claro que "sob estímulos iguais, pessoas diferentes reagem distintamente e a mesma pessoa em diferentes situações reage de forma diferenciada”. Condições iguais num ambiente podem conduzir diferentes indivíduos a comportamentos distintos, assim como diferentes condições do meio ambiente podem levar uma pessoa a comportamentos iguais.

Além da percepção, a vulnerabilidade é outro fator individual que interfere na possível instalação de quadros de estresse. Representa a capacidade do indivíduo de enfrentar e suportar a situação de pressão na qual se encontra. Couto (1987) considera que todos os indivíduos apresentam um limite para suportar a pressão. Pessoas com maior vulnerabilidade têm menor capacidade de enfrentamento e acabam por sofrer com pressões de pequena intensidade. Já indivíduos com menor vulnerabilidade possuem uma estrutura psíquica mais rígida e apresentam maiores resistências individuais às situações de pressão. Mas quando os limites individuais são ultrapassados, o resultado é a tensão, podendo até resultar no estresse.

Para Simonton et al. (1987), os indivíduos que normalmente são mais propensos ao estresse são aqueles que não conseguem, ou não se permitem, relaxar, ou mesmo se refazer de uma situação de tensão, passando imediatamente a lidar com outras, atingindo, dessa forma, um estado de estresse. O quadro de estresse indica que o indivíduo pode estar adoecendo e requer, portanto, intervenções terapêuticas para minimizar e combater a sintomatologia apresentada, assim como enfrentar de maneira mais positiva as causas indutoras e as situação vivenciada.

1.2.1 Modelo de referência para o estudo do estresse ocupacional

O modelo teórico para explicar o estresse ocupacional em gerentes (MTEG), desenvolvido e validado por Zille (2005), tendo como referência Levi (2005) Cooper et al. (1988); Karasek et al. (2000, 1998); Karasek e Torres (1996); Couto (1987), serviu de

REAd | Porto Alegre - Edição 79 - N 3 - setembro/dezembro 2014 - p. 658-680 
Estresse no trabalho: estudo com gestores públicos do estado de Minas Gerais

referência para o desenvolvimento deste estudo. De acordo com Zille (2005), a manifestação do estresse está relacionada ao desequilíbrio acentuado entre os níveis de tensão que o indivíduo recebe do meio ocupacional e à sua capacidade psíquica de suportá-lo.

Tal modelo está estruturado em cinco construtos de primeira ordem: fontes de tensão no trabalho (FTT); fontes de tensão do indivíduo e do papel gerencial (FTIPG); mecanismos de regulação (MECREGUL); sintomas de estresse (SINTOMAS) e indicadores de impactos na produtividade (IMPACTOS). Os construtos de primeira ordem são explicados por construtos de segunda ordem, que, por sua vez, são explicados pelos indicadores correspondentes, sendo que a exceção se faz ao construto IMPACTO, que é explicado diretamente pelos seus indicadores.

Os processos de trabalho, relações de trabalho, insegurança nas relações de trabalho e convivência com indivíduos de personalidade difícil são construtos de segunda ordem, que explicam as FTT. Responsabilidades acima dos limites, estilo e qualidade de vida, aspectos específicos do trabalho do gerente e motivação são construtos de segunda ordem, que explicam as FTIPG. Já interação e prazos, descanso regular, experiência no trabalho e atividade física também são construtos de segunda ordem, mas que explicam os MECREGUL. Finalmente, os construtos de segunda ordem que explicam os SINTOMAS são a hiperexcitabilidade e senso de humor; sintomas psíquicos e do sistema nervoso simpático (SNS) e gástrico; os sintomas de aumento do tônus, tontura/vertigem, falta/excesso de apetite e relaxamento.

\section{MÉTODO}

Trata-se de pesquisa descritiva, com abordagem quantitativa (GIL, 1999; VERGARA, 2000). Quanto aos meios foi realizado um survey (MARTINS e THEÓPHILO, 2009; GIL, 1999).

Como unidades de análise têm-se as secretarias de estado que compõem a administração direta do estado de Minas Gerais. A pesquisa foi de caráter censitário, envolvendo a totalidades dos sujeitos (617) objetos do estudo, que se constituíram dos servidores da administração pública direta do estado de Minas Gerais que ocupam funções gerenciais e atuam nas Secretarias de Estado. Tal escolha se deu de forma intencional, tendo em vista três fatores: a) as significativas mudanças administrativas por que passou e ainda passa o estado mineiro, sendo, portanto, importante investigar os impactos de tais mudanças 
nos ocupantes de funções gerenciais (gestores); b) a concentração destes profissionais num mesmo local de trabalho (Cidade Administrativa), mantendo estável a variável ambiente de trabalho; e c) a continuidade das ações e do planejamento do governo do estado, que desde 2003 implanta o Choque de Gestão.

Para a coleta dos dados utilizou-se o questionário aderente ao MTEG (ZILLE, 2005), adaptado para este estudo. Para o processamento dos dados quantitativos foram utilizados os softwares Excel 2007 e o Statistical Package for the Social Sciences (SPSS), versão 18. Foram realizadas as análises descritivas, envolvendo análise exploratória dos dados, de frequência, análises bivariadas e ainda testes para médias e proporções. Em todos os testes estatísticos utilizados foi considerado um nível de significância de 5\%; dessa forma, os resultados estatisticamente significativos foram aquelas cujo valor $\mathrm{p}$ foi menor ou igual a 0,05 $(\mathrm{p}<=0,05)$.

\section{RESULTADOS E ANÁLISE}

Ao analisar os dados demográficos dos 181 gestores efetivamente participantes, obteve-se os seguintes resultados: 57,4\% do sexo feminino, 33,8\% possuem de 25 a 34 anos, 50,8\% casados e 96,1\% com curso superior completo. Em relação aos hábitos de vida: 63\% consomem bebida alcoólica, 11\% fumam e 31,5\% praticam atividade física de forma regular. Dados funcionais obtidos: 65\% são concursados, 61,3\% ocupam a função de diretor, 52,5\% estão de 1 a 3 anos no cargo de gestão e 71,3\% trabalham mais de 40 horas semanais. Quanto à ocorrência de problemas de saúde, 40,3\% afirmaram ter apresentado alguma queixa nos últimos três meses, sendo que as mais recorrente foram: hipertensão, citada por 31 gestores, gastrite, citada por 15 gestores, hipotireoidismo, diabetes e problemas respiratórios, cada um citado por 5 gestores. Dois gestores relataram já ter sofrido infarto cardíaco. De uma forma geral, estas patologias são apontadas pela literatura como relacionadas ao estresse (LEVI, 2003, 2005); (COOPER et al., 1988); ALBRECHT (1990) e COUTO (1987), embora esta análise não seja objetivo deste estudo.

\subsection{Análise do estresse ocupacional}

Para o diagnóstico do estresse ocupacional utilizou-se como referência os parâmetros do MTEG, desenvolvido por Zille (2005), adaptado para este estudo. Foram considerados

REAd | Porto Alegre - Edição 79 - N 3 - setembro/dezembro 2014 - p. 658-680 
Estresse no trabalho: estudo com gestores públicos do estado de Minas Gerais

quatro níveis para análise do estresse com os seguintes valores de referência: ausência de estresse: <1,75; estresse leve a moderado: $>$ ou $=1,75$ e $<2,46$; estresse intenso: $>$ ou igual 2,46 e < 3,16; estresse muito intenso: > ou = 3,16; numa escala de 5 pontos (ZILLE, 2005, p. 222, 223).

A Tabela 1 apresenta a análise descritiva do nível de estresse dos gestores mineiros pesquisados. Os que apresentaram quadro de estresse instalados, variando de leve a moderado a muito intenso, foram 134, ou 74,0\%. São 78 gestores, ou 43,0\%, com nível de estresse leve a moderado; 47 gestores, ou 26,0\%, com estresse intenso; e 9 gestores, ou 5,0\%, com estresse muito intenso. Os participantes que não apresentaram quadro de estresse foram 47, ou 26,0\%, o que significa que estes indivíduos vêm apresentando bom equilíbrio entre suas estruturas psíquicas e as exigências psíquicas advindas das situações de trabalho.

Tabela 1 - Análise descritiva do nível de estresse ocupacional

\begin{tabular}{|c|c|c|c|c|c|c|c|c|c|}
\hline Nível de estresse & $\mathbf{N}$ & $\%$ & Média & Mediana & $\begin{array}{l}\text { Desvio } \\
\text { Padrão }\end{array}$ & Mín. ${ }^{1}$ & Max. $^{2}$ & $\begin{array}{c}\text { Perc. }^{3} \\
25 \\
\end{array}$ & $\begin{array}{c}\text { Perc. } \\
75 \\
\end{array}$ \\
\hline Ausência de estresse & 47 & 26,0 & 1,45 & 1,49 & 0,211 & 1,00 & 1,75 & 1,28 & 1,64 \\
\hline Estresse leve a moderado & 78 & 43,0 & 2,08 & 2,08 & 0,199 & 1,76 & 2,45 & 1,93 & 2,24 \\
\hline Estresse intenso & 47 & 26,0 & 2,75 & 2,70 & 0,197 & 2,48 & 3,15 & 2,58 & 2,97 \\
\hline Estresse muito intenso & 9 & 5,0 & 3,42 & 3,27 & 0,392 & 3,17 & 4,41 & 3,20 & 3,51 \\
\hline Total & 181 & 100,0 & 2,16 & 2,12 & 0,592 & 1,00 & 4,41 & 1,74 & 2,58 \\
\hline
\end{tabular}

Nota: 1) abreviação de mínimo. 2) abreviação de máximo. 3) abreviação de percentil

O resultado do estresse em relação aos gestores pesquisados vai ao encontro dos resultados das últimas pesquisas realizadas no Brasil sobre o tema. Zille (2005) realizou estudo em que avaliou o nível de estresse gerencial em 15 empresas privadas com atuação no Brasil. O resultado final da amostra, constituída por 547 indivíduos, revelou que 63\% dos gerentes apresentaram quadro de estresse, sendo que $45 \%$ com nível de estresse leve a moderado, $15 \%$ com estresse intenso e 3\% com nível de estresse muito intenso. Outro estudo realizado por Zille et al. (2011), com uma amostra de 950 gestores pesquisados, apontou os seguintes resultados: $71 \%$ com quadro de estresse, sendo que $43 \%$ com quadro de estresse leve a moderado, 23\% com estresse intenso e 5\% com nível de estresse muito intenso. Ressalta-se que, apesar de o estudo em referência ter sido realizado na esfera pública, os resultados são similares aos encontrados com gerentes e outros trabalhadores na realidade brasileira (ZILLE, 2011, 2005; COUTO, 1987). 


\subsubsection{Sintomas de estresse}

Neste estudo, a incidência dos sintomas em cada um dos gestores serviu de base para o diagnóstico do nível de estresse ocupacional. A escala utilizada no questionário para mensurar a frequência com que os sintomas manifestaram nos gestores, variou de 1,00 a 5,00, com as seguintes gradações: nunca, raramente, algumas vezes, frequente e muito frequente. Os gestores que manifestaram o sintoma de forma frequente ou muito frequente, de acordo os valores de referência constantes da escala apresentada no item 3.1 foram identificados e distribuídos conforme o diagnóstico de estresse (grupo sem estresse e grupo com estresse).

Foi possível perceber que todos os sintomas relacionados ao estresse ocupacional foram significativamente mais frequentes no grupo de gestores com estresse do que no grupo de gestores sem estresse. Fadiga (58,96\%) e dor nos músculos do pescoço (50,75\%) foram os sintomas físicos mais recorrentes e manifestaram em mais da metade dos gestores com estresse. Ansiedade (46,27\%) e angústia (34,33\%), sintomas psíquicos, manifestaram em mais de um terço dos gestores com estresse. Nervosismo (30,60\%) e irritabilidade fácil (26,87\%) ocorreram em mais de um quarto dos estressados.

\subsubsection{Fontes de tensão}

As fontes de tensão analisadas são constituídas por dois construtos distintos: fontes de tensão no trabalho e fontes de tensão do indivíduo e do papel gerencial.

Foi possível identificar que todos os indicadores do construto 'fontes de tensão no trabalho’ foram significativamente superiores no grupo de gestores com estresse. Os cinco indicadores mais importantes apontados pelos gestores com estresse foram: "realização de várias atividades ao mesmo tempo, com alto grau de cobrança” (49,64\%), "muitos prazos e prazos apertados na execução do trabalho" (40,88\%) e "realização do máximo de trabalho com o mínimo de recursos, de forma exagerada” (35,04\%).

Outro construto importante está relacionado às fontes de tensão do indivíduo e do papel gerencial. Em relação às fontes de tensão do indivíduo os indicadores mais significativos e que se apresentaram em mais da metade dos gestores com estresse, foram: "pensar e/ou realizar frequentemente duas ou mais coisas ao mesmo tempo, com dificuldade de concluí-las, mesmo quando não há exigências para tal” (62,77\%), “ter o dia muito tomado 
Estresse no trabalho: estudo com gestores públicos do estado de Minas Gerais

com uma série de compromissos assumidos, com pouco ou nenhum tempo livre” (62,04\%), "levar a vida de forma muito corrida, realizando cada vez mais trabalho em menos tempo, mesmo quando não há exigências para tal” (59,85\%) e “não conseguir se desligar do trabalho” (52,55\%).

Já em relação às fontes de tensão específicas do trabalho do gerente, os indicadores mais significativos observados no grupo de gestores com estresse foram: "não ter tempo para viver com mais qualidade de vida, apresar de ter consciência desta necessidade” (58,96\%) e “vivenciar conflitos decorrentes da necessidade de ser inovador e dotado de autonomia e ao mesmo tempo ter que se subordinar às normas institucionais” (51,49\%), "ter dificuldade de conciliar vida profissional e pessoal” (47,76\%) e "vivenciar conflitos por perceber-se em sobrecarga e não ter como questionar a situação, por exercer função de gestor” (44,78\%).

\subsubsection{Mecanismos de regulação e indicadores de impactos na produtividade}

Quanto aos mecanismos de regulação apresentados pelos gestores para minimizar os efeitos do estresse, foi identificado que "experiência pessoal na solução de dificuldades no trabalho" (100,00\%) e "possibilidade de descansar, de forma regular, nos feriados e finais de semana” (100,00\%) foram os recursos utilizados por todos os gestores com ausência de estresse. “Tempo disponível para relaxar/descansar” (82,93\%), “cooperação entre os pares (gestores)” (80,49\%) e “possibilidade de gozar férias regularmente” (78,05\%) também foram mecanismos utilizados por mais de três quartos dos gestores sem estresse.

Houve alta frequência dos indicadores do construto 'mecanismos de regulação' também no grupo de gestores diagnosticados com quadro de estresse (média de 38,66\%). Isso indica que apesar das estratégias utilizadas por estes gestores para o enfrentamento das exigências psíquicas do ambiente (laboral ou não), estas não estão sendo resolutivas. No entanto, é possível afirmar que se houvesse a inexistência destas estratégias, o impacto do estresse poderia seria bem maior. Se estas estratégias não resolvem o problema, pelo menos podem atenuá-lo.

No grupo de gestores com estresse, os principais indicadores de impacto na produtividade, por ordem de importância, foram: “lapsos de memória” (29,85\%), “desejo de trocar de emprego" (25,37\%), “dificuldade de concentração” (24,63\%) e “desmotivação com o trabalho” (23,13\%). Dois destes indicadores, redução da memória e dificuldade de concentração, estão relacionados ao desgaste mental, sendo que os outros dois estão 
relacionados à insatisfação e à consequente desmotivação com o trabalho. Conforme Zanelli (2010), o desgaste leva o trabalhador a perder parte da capacidade psicológica e biológica, o que de certa forma trará impacto no trabalho.

\subsection{Relações do estresse ocupacional com variáveis demográficas, ocupacionais e hábitos de vida}

Analisou-se a relação entre os níveis de estresse ocupacional e variáveis demográficas (sexo, idade, estado civil e escolaridade), funcionais (vínculo trabalhista, nível hierárquico, horas semanais trabalhadas, tempo na função de gestão) e hábitos de vida (consumo de cigarro, álcool e prática de atividade física). Foi encontrada significativa diferença estatística ( $\mathrm{p}=0,007$ ) na média do nível de estresse dos gestores viúvos quando comparados aos casados, solteiros e outros. Pode-se afirmar que os gestores viúvos apresentaram menores níveis de estresse quando comparados aos solteiros, casados e com outro vínculo conjugal. O teste qui-quadrado, realizado com a variável nível de estresse dicotomizada em gestores com estresse e sem estresse indicou associação $(p=0,028)$ entre o estado civil dos gestores pesquisados e o estresse ocupacional.

Quando se trata da relação entre o consumo de bebida alcoólica e o estresse ocupacional, foi possível perceber que os gestores que fazem uso de bebida alcoólica apresentaram a maior proporção entre os indivíduos com quadros de estresse, indicando existir associação entre o consumo de bebida alcoólica e o estresse ocupacional ( $p=0,008)$.

A relação entre o hábito de fumar e o nível de estresse ocupacional demonstrou que os indivíduos que têm o hábito de fumar apresentaram alta proporção entre os gestores com estresse intenso e muito intenso. Houve diferença estatisticamente significativa $(p=0,001)$ na média do nível de estresse ocupacional dos fumantes e dos não fumantes. Quem fuma tem nível de estresse maior do que quem não fuma. O teste do qui-quadrado, considerando a variável nível de estresse estratificada em seus quatro níveis indicou associação $(p=0,004)$ entre o consumo de cigarros e o estresse ocupacional.

Os gestores que praticam atividade física de forma regular tiveram maior proporção de indivíduos com ausência de estresse quando comparados aos gestores que não realizam esta prática. Houve diferença estatisticamente significativa $(\mathrm{p}=0,005)$ na média do nível de estresse ocupacional dos praticantes de atividade física e não praticantes. Quem pratica atividade física tem menores níveis de estresse do que quem não pratica. O teste do qui- 
Estresse no trabalho: estudo com gestores públicos do estado de Minas Gerais

quadrado, considerando a variável nível de estresse dicotomizada em gestores com estresse e sem estresse indicou associação $(p=0,039)$ entre a prática de atividade física e o estresse ocupacional.

\section{CONSIDERAÇÕES FINAIS}

Este estudo teve como objetivo geral identificar e analisar os quadros de estresse ocupacional, suas causas, principais sintomas, mecanismos de regulação e indicadores de impactos na produtividade dos trabalhadores que exercem a função de gestor nas secretarias de estado de Minas Gerais, tendo como referência o modelo teórico de explicação do estresse ocupacional em gerentes - MTEG (ZILLE, 2005).

Ao se analisar o nível de intensidade do estresse ocupacional dos gestores públicos, identificou-se que 74\% apresentam quadro de estresse, variando de leve a moderado (43,0\%), estresse intenso (26,0\%) e muito intenso (5,0\%). Somente 26\% dos gestores não apresentaram manifestações de estresse. Esses resultados são semelhantes aos encontrados por Zille (2011), Zille, Braga e Zille (2011); Braga (2008), Zille (2005) e Couto (1987) ao investigarem gerentes de organizações privadas brasileiras. Em relação aos principais sintomas do grupo de gestores com estresse também se verificou semelhança com os estudos em referência.

Foi possível constatar que as principais fontes de tensão no trabalho identificadas estão relacionadas ao construto de segunda ordem processos de trabalho, componente do modelo teórico MTEG. Isso indica que os resultados encontrados estão de acordo com estudos que apresentam como principais fontes de tensão no trabalho: sobrecarga e pressão no trabalho (ZANELLI, 2010; CAMELO e ANGERAMINI, 2008; ZILLE 2005; SINGH e DUBEY, 2001) e complexidade e estruturação do trabalho (JUNQUILHO, 2005; ROSH, 2005).

$\mathrm{Na}$ análise das fontes de tensão específicas do trabalho do gerente foi possível concluir que, conforme Chanlat (2005), os estudos sobre gerentes têm revelado que uma das importantes fontes de estresse potencialmente prejudicial à saúde são as características do trabalho. Ao se considerar as fontes de tensão relatadas neste estudo, é reforçada a afirmação de Johnson et al. (2009) de que as pessoas que trabalham em ocupações com alta carga de tensão diária terão uma maior probabilidade de vivenciar as condições negativas do estresse. Nessa direção, Davel e Melo (2005) relatam que entre as ocupações com alta carga de tensão diária estão os gestores, fato este também percebido por meio deste estudo. 
Quanto aos mecanismos de regulação, pode-se concluir que o construto em referência mostrou-se importante para explicar a ausência de estresse em $26 \%$ dos gestores pesquisados. De acordo com Simonton et al. (1987), os indivíduos que normalmente são mais propensos ao estresse são aqueles que não conseguem, ou não se permitem relaxar, ou mesmo se refazer de uma situação de tensão, passando imediatamente a lidar com outras, atingindo, dessa forma, um estado de estresse. Essa afirmação foi reforçada com este estudo, pois o mecanismo 'tempo disponível para relaxar/descansar' foi utilizado com frequência significativamente superior pelos gestores sem estresse (82,93\%) quando comparados aos gestores com estresse (23,13\%).

Em relação aos indicadores de impacto na produtividade, é possível concluir que, assim como relatado por Levi (2008), o trabalho afeta a saúde, mas a saúde do trabalhador também afeta a produtividade do indivíduo e sua capacidade de ganhar o sustento, bem como suas relações sociais e familiares. Isso se aplica a todos os aspectos da saúde, tanto física quanto mental.

A análise dos níveis de estresse em subgrupos estratificados por variável demográfica e por variável funcional permitiu constatar que as variáveis estado civil, hábito de fumar e prática de atividade física apresentaram diferença estatisticamente significativa na média do nível de estresse de suas categorizações $(p<0,05)$. Ou seja, os gestores viúvos apresentaram menores níveis de estresse quando comparados com os solteiros, casados e outro tipo de vínculo conjugal. Em relação ao hábito de fumar, foi constatado que os fumantes apresentaram maiores níveis de estresse quando comparados com os não fumantes. Já os praticantes frequentes de atividades físicas apresentaram menores níveis de estresse do que os não praticantes.

Houve associação entre o consumo de cigarros e o estresse ocupacional e também entre o consumo de álcool e o estresse ocupacional $(\mathrm{p}<0,05)$. Alguns gestores podem acreditar que o fumo ou o álcool estejam funcionando como mecanismo de regulação do estresse. Mas deve-se considerar que eles podem estar funcionando como retroalimentação para a manutenção e o agravamento dos quadros de estresse, tendo em vista que a nicotina e o álcool, nas primeiras doses, são drogas estimulantes, podendo servir como “combustível” para o estresse.

Também houve associação entre a prática de atividade física e o estresse $(\mathrm{p}<0,05)$. A prática de atividade física funciona como um mecanismo de regulação contra o estresse. Este resultado está em conformidade com o estudo de Tamayo (2001), Canova e Porto (2010) e 
Estresse no trabalho: estudo com gestores públicos do estado de Minas Gerais

Zille (2005). De acordo com Tamayo (2001), a explicação pode ser de ordem fisiológica, pois o exercício físico regular desenvolve o condicionamento cardiovascular, que, por sua vez, provoca a redução, na corrente sanguínea, da taxa de diversas substâncias associadas ao estresse, de ordem psicossocial. As várias modalidades de atividade física propiciam a interação social, por corroborar no sentido da satisfação do indivíduo ao realizar uma meta socialmente desejável, sugerida, recomendada.

Algumas limitações servem como sugestões para pesquisas futuras. Este trabalho se limitou ao estudo dos gestores públicos estaduais que trabalham na Cidade Administrativa, sendo que a generalização dos resultados está limitada a tais sujeitos. Disso surge a possibilidade de investigar os possíveis quadros de estresse ocupacional nos demais gestores do Estado, como também nos planos federal e municipal. Tais limitações foram intencionais, mas permitem vislumbrar novos campos de pesquisa.

Espera-se que este trabalho, a partir dos dados e resultados apresentados, possa contribuir com o balizamento de projetos institucionais do Estado de Minas Gerais para redução ou controle dos níveis de estresse ocupacional dos gestores. Dessa forma, poderá gerar melhorias nas condições de trabalho e na qualidade de vida desses trabalhadores, bem como criar condições favoráveis para melhoria dos serviços prestados à sociedade mineira.

Finalmente, reforçando Albrecht (1990), as organizações devem investir na redução do estresse no trabalho como forma de manter os gestores saudáveis e produtivos. Além disso, também se deve evitar o estresse, com seu efeito negativo e contagioso, que pode ser transferido para outros trabalhadores, possibilitando um desencadeamento em cascata, levando a uma epidemia de estresse, que tem um efeito nefasto sobre os trabalhadores e as organizações.

\section{REFERÊNCIAS}

ABRUCIO, L. F. Os avanços e os dilemas do modelo pós-burocrático: a reforma da administração pública à luz da experiência internacional recente. In: BRESSER-PEREIRA, L. C.; SPINK, P. (Orgs.). Reforma do Estado e administração pública gerencial. 7. ed. Rio de Janeiro: FGV, 2006.

ABRUCIO, F. L. O impacto do modelo gerencial na administração pública: um breve estudo sobre a experiência internacional recente. Cadernos ENAP, n. 10. Brasília: ENAP, 1997.

ALBRECHT, K. O gerente e o estresse: faça o estresse trabalhar para você. Rio de Janeiro: Jorge Zahar, 1990.

REAd | Porto Alegre - Edição 79 - N 3 - setembro/dezembro 2014 - p. 658-680 
ARROBA, T.; JAMES, K. Pressão no trabalho: um guia de sobrevivência para gerentes e executivos. 2. ed. São Paulo: Makron Books, 1994.

BALASSIANO, M; TAVARES, E. PIMENTA, R. C. Estresse ocupacional na administração pública brasileira: quais fatores impactantes? Revista de Administração Pública, Rio de Janeiro, v. 45, n. 3, p. 751-774, maio/jun. 2011.

BRAGA, C. D. As novas tecnologias de gestão e suas decorrências: as tensões no trabalho e o estresse ocupacional na função. 2008. Dissertação (Mestrado em Adminis-tração) Centro de Pós-Graduação e Pesquisas em Administração, Universidade Fede-ral de Minas Gerais, Belo Horizonte, 2008.

BRESSER-PEREIRA, L. C. Construindo o estado republicano: democracia e reforma da gestão pública. Rio de Janeiro: FGV, 2009.

CAMELO, S. H. H.; ANGERAMI, E. L. S. Riscos psicossociais no trabalho que podem levar ao estresse: uma análise da literatura. Ciência, Cuidado e Saúde, Maringá, n. 7, v. 2, p. 232240, abr./jun. 2008.

CAMPOS, E. S. A.; GUIMARÃES, T. B. Gestão por resultados em Minas Gerais: análise crítica arranjo incremental de monitoramento e avaliação. In: ENCONTRO ANUAL DA ASSOCIAÇÃO NACIONAL DE PROGRAMAS DE PÓS-GRADUAÇÃO EM ADMINISTRAÇÃO, 33, 2009, São Paulo. Anais... São Paulo: ANPAD, 2009. 1 CD-ROM.

CANOVA, K., R.; PORTO, J. B. O impacto dos valores organizacionais no estresse ocupacional: um estudo com professores do ensino médio. Revista de Administração Mackenzie, São Paulo, v. 11, n. 5, set./out. 2010.

CHANLAT, J. F. Mitos e realidades sobre o estresse dos gerentes. In: DAVEL, E., MELO, M. C. O. (Orgs.) A gerência em ação: singularidades e dilemas do trabalho gerencial. Rio de Janeiro: FGV, 2005.

COOPER, C. L.; COOPER, R. D.; EAKER, L. H. Living with stress. London: Penguin Books, 1988.

COUTO, H. A. Stress e qualidade de vida dos executivos. Rio de Janeiro: COP, 1987.

DAVEL, E.; MELO, M. C. O. (Orgs.). A gerência em ação: singularidades e dilemas do trabalho gerencial. Rio de Janeiro: FGV, 2005.

GIL, A. C. Métodos e técnicas de pesquisa social. São Paulo: Atlas, 1999.

ISMA - BR. International Stress Management Association. Brasil, 2010. (Boletim) 
Estresse no trabalho: estudo com gestores públicos do estado de Minas Gerais

JOHNSON, S. et al. A vivência do stress relacionado ao trabalho em diferentes ocupações. In: ROSSI, A. M.; QUICK, J. C.; PERREWÉ, P. L. (Orgs.). Stress e qualidade de vida no trabalho: o positivo e o negativo. São Paulo: Atlas, 2009.

JUNQUILHO, G. S. Administração pública e gerentes no contexto brasileiro. In: DAVEL, E.; MELO, M. C. O. (Orgs.). A gerência em ação: singularidades e dilemas do trabalho gerencial. Rio de Janeiro: FGV, 2005.

KARASEK, R.; TORRES, T. Current issues relating to psychosocial job strain and cardiovascular. Journal of Occupational Health Psychology. v. 1, n. 1, p. 9-26, 1996.

KARASEK, R. et al. Psychosocial factores : review of the empirical data among men. Philadelphia: Hanley \& Belfus, Inc. Occupational Medicine, v. 15, n. 1, January-march, 2000 .

KARASEK, R. et al. The job content questionnaire (JCQ): an instrument for internationally comparative assessments of psychosocial job characteristics. Educational Publishing Fundation. Journal of Occupational Health Psychology. v. 3, n. 4, p. 322-355, 1998.

LEVI, L. O guia da comissão europeia sobre stress relacionado ao trabalho e iniciativas relacionadas: das palavras à ação. In: ROSSI, A. M.; PERREWÉ, P. L.; SAUTER, S. L. (Orgs.). Stress e qualidade de vida no trabalho: perspectivas atuais da saúde ocupacional. São Paulo: Atlas, 2008.

LEVI, Lennart. Sociedade, stress e doença - investimentos para a saúde e desenvolvimento: causas, mecanismos, conseqüências, prevenção e promoção. V Congresso de Stress da ISMA-BR (International Stress Management Associaation) e VII Fórum Internacional de Qualidade de Vida no Trabalho. Porto Alegre: Anais ... 2005.

LEVI, Lennart. Sociedade, Stress e Doença - Investimentos para a saúde e desenvolvimento: causas, mecanismos, consequências, prevenção e promoção. III Congresso de Stress da ISMA-BR (International Stress Management Associaation) e V Fórum Internacional de Qualidade de Vida no Trabalho. Porto Alegre: Anais ... 2003.

LIPP, M. E. N. Stress e o turbilhão da raiva. São Paulo: Caso do Psicólogo, 2005.

MADUREIRA, C.; RODRIGUES, M. A. Administração pública do século XXI: aprendizagem organizacional, mudança comportamental e reforma administrativa. Comportamento Organizacional e Gestão, Oeiras, vol. 12, n. 2, p. 153-171, 2006.

MARINI, C. O contexto contemporâneo da administração pública na América Latina. Revista do Serviço Público, Brasília, ano 53, n. 4, p. 31-52, out./dez. 2002.

MARTINS, G. A.; THEÓPHILO, C. R. Metodologia da investigação científica para ciências sociais aplicadas. São Paulo: Atlas, 2009.

REAd | Porto Alegre - Edição 79 - N 3 - setembro/dezembro 2014 - p. 658-680 
MELO, M. C. O. L.; CASSINI, M. R. O. L; LOPES, A. L. M. Do estresse e mal-estar gerencial ao surgimento da síndrome de Estocolmo gerencial. Revista Psicologia: Organizações e Trabalho, Brasília, v. 11, n. 2, p. 84-99, jul./dez. 2011.

MINAS GERAIS (Estado). Portal Governo de Minas Gerais. Conheça Minas. Dados Gerais. [2012]. Disponível em: <http://www.mg.gov.br/governomg/portal/c/governomg/conhecaminas/geografia/9940-dados-gerais-minas/5681-dados-gerais/5146/5044>. Acesso em 20 mar. 2012.

MINAS GERAIS (Estado). Lei $\mathbf{n}^{\mathbf{0}} \mathbf{1 7 . 6 0 0}$, de $\mathbf{1}^{\mathbf{0}}$ de julho de 2008. Disciplina o Acordo de Resultados e o Prêmio por Produtividade no âmbito do Poder Executivo e dá outras providências. Belo Horizonte, 2008. Disponível em: $<$ http://www.almg.gov.br/consulte/legislacao/completa/completa.html?tipo=LEI\&num=17600

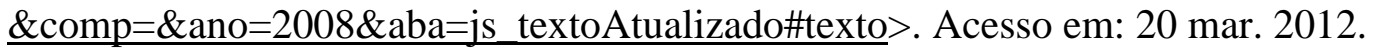

ORGANIZAÇÃO PARA COOPERAÇÃO E DESENVOLVIMENTO ECONÔMICO. Avaliação da gestão de recursos humanos no governo: relatório da OCDE 2010. Brasil: Governo Federal, 2010.

REZENDE, F. C. O dilema do controle e a falha sequencial nas reformas gerenciais. Revista do Serviço Público, Brasília, ano 53, n.3, p. 50-74, jul./set. 2002.

RIO, R. P. O fascínio do stress. Belo Horizonte: Del Rey, 1995.

ROSH, P. J. O comportamento tipo “A” propenso a problemas coronarianos, stress no trabalho e doença cardíaca. In: ROSSI, A. M.; PERREWÉ, P. L.; SAUTER, S. L. (Orgs.). Stress e qualidade de vida no trabalho: perspectivas atuais da saúde ocupacional. São Paulo: Atlas, 2005.

ROSSI, A. M. Apresentação ISMA-BR. In: ROSSI, A. M.; QUICK, J. C.; PERREWÉ, P. L. (Orgs.). Stress e qualidade de vida no trabalho: o positivo e o negativo. São Paulo: Atlas, 2009.

SAMULSKI, D.; CHAGAS, M. H.; NITSCH, J. R. Stress: teorias básicas. Belo Horizonte:Costa \& Cupertino, 1996.

SELYE, H. Stress: a tensão da vida. São Paulo: IBRASA, 1959.

SIMONTON, C. et al. Com a vida de novo: abordagem de autoajuda para pacientes com câncer. São Paulo: Summus, 1987.

SINGH, A. P.; DUBEY, A. K. The power of momentum: a new model of dynamic relationships between job satisfaction change and turnover intentions. Academy of Management Journal, vol. 54, Issue 1, p. 159-181, feb. 2011. 
Estresse no trabalho: estudo com gestores públicos do estado de Minas Gerais

TAMAYO, A. Prioridades axiológicas, atividade física e estresse ocupacional. Revista de Administração Contemporânea, Rio de Janeiro, v. 5, n. 3, set./dez. 2001.

VERGARA, S. C. Projetos e relatórios de pesquisa em administração. São Paulo: Atlas, 2000 .

VILHENA, R.; MARTINS, H. F.; MARINI, C. Introdução. In: VILHENA, R.; MARTINS, H. F.; MARINI, C.; GUIMARÃES, T. B. O choque de gestão em Minas Gerais: políticas da gestão pública para o desenvolvimento. Belo Horizonte: Editora UFMG, 2006.

ZANELLI, J. C. et al. Estresse nas organizações de trabalho: compreensão e intervenção baseadas em evidências. Porto Alegre: Artmed, 2010.

ZILLE, L. P. Novas perspectivas para abordagem do estresse ocupacional em gerente: estudos em organizações brasileiras de diversos setores. Belo Horizonte: CEPEAD/FACE/UFMG, 2005 (Tese de Doutorado).

ZILLE, L. P.; BRAGA, C. D.; MARQUES, A. L. Estresse no trabalho: estudo de caso com gerentes que atuam em uma instituição financeira nacional de grande porte. Revista de Ciências da Administração, Florianópolis, v. 10, n. 21, p. 175-196, mai./ago. 2008.

ZILLE, L. P.; BRAGA, C. D.; ZILLE, G. P. Estresse ocupacional: como os gestores brasileiros estão respondendo às transformações na função gerencial? In: SANT'ANNA, A. S.; KILIMNIK, Z. M. (Orgs.). Qualidade de vida no trabalho: abordagens e fundamentos. Belo Horizonte: Fundação Dom Cabral, 2011.

ZILLE, L. P. O estresse e os impactos no trabalho na função gerencial: buscando as interfaces da realidade brasileira e portuguesa. In: BARBOSA, A. C. e SILVA, J. R. (Orgs.). Economia, gestão e saúde: as relações luso-brasileiras em perspectiva. Lisboa: Edições Colibri, 2011. 